\title{
Heme oxygenase-I prevents smoke induced B-cell infiltrates: a role for regulatory $T$ cells?
}

\author{
Corry-Anke Brandsma*1,2, Machteld N Hylkema², Barry WA van der Strate ${ }^{1,2}$, \\ Dirk-Jan Slebos $^{1}$, Marjan A Luinge ${ }^{1,2}$, Marie Geerlings ${ }^{1,2}$, Wim Timens ${ }^{2}$, \\ Dirkje S Postma ${ }^{1}$ and Huib AM Kerstjens ${ }^{1}$
}

Address: ${ }^{1}$ Department of Pulmonary Diseases, University Medical Center Groningen, University of Groningen, P.O. Box 30.001, 9700 RB, Groningen, The Netherlands and 2Department of Pathology, University Medical Center Groningen, University of Groningen, P.O. Box 30.001, 9700 RB, Groningen, The Netherlands

Email: Corry-Anke Brandsma* - c.a.brandsma@path.umcg.nl; Machteld N Hylkema - m.n.hylkema@path.umcg.nl; Barry WA van der Strate - b.w.a.van.der.strate@med.umcg.nl; Dirk-Jan Slebos - d.j.slebos@int.umcg.nl; Marjan A Luinge - m.luinge@path.umcg.nl; Marie Geerlings - m.geerlings@path.umcg.nl; Wim Timens - w.timens@path.umcg.nl; Dirkje S Postma - d.s.postma@int.umcg.nl; Huib AM Kerstjens - h.a.m.kerstjens@int.umcg.nl

* Corresponding author

Published: 6 February 2008

Respiratory Research 2008, 9:17 doi:10.1186/1465-9921-9-17
Received: 10 July 2007

Accepted: 6 February 2008

This article is available from: http://respiratory-research.com/content/9/1/17

(c) 2008 Brandsma et al; licensee BioMed Central Ltd.

This is an Open Access article distributed under the terms of the Creative Commons Attribution License (http://creativecommons.org/licenses/by/2.0), which permits unrestricted use, distribution, and reproduction in any medium, provided the original work is properly cited.

\begin{abstract}
Background: Smoking is the most important cause for the development of COPD. Since not all smokers develop COPD, it is obvious that other factors must be involved in disease development. We hypothesize that heme oxygenase-I (HO-I), a protective enzyme against oxidative stress and inflammation, is insufficiently upregulated in COPD.
\end{abstract}

The effects of HO-I modulation on cigarette smoke induced inflammation and emphysema were tested in a smoking mouse model.

Methods: Mice were either exposed or sham exposed to cigarette smoke exposure for 20 weeks. Cobalt protoporphyrin or tin protoporphyrin was injected during this period to induce or inhibit HO-I activity, respectively. Afterwards, emphysema development, levels of inflammatory cells and cytokines, and the presence of B-cell infiltrates in lung tissue were analyzed.

Results: Smoke exposure induced emphysema and increased the numbers of inflammatory cells and numbers of B-cell infiltrates, as well as the levels of inflammatory cytokines in lung tissue. HOI modulation had no effects on smoke induced emphysema development, or the increases in neutrophils and macrophages and inflammatory cytokines. Interestingly, $\mathrm{HO}-\mathrm{I}$ induction prevented the development of smoke induced B-cell infiltrates and increased the levels of CD4+CD25+ $T$ cells and Foxp3 positive cells in the lungs. Additionally, the $C D 4^{+} C D 25^{+} T$ cells correlated positively with the number of Foxp3 positive cells in lung tissue, indicating that these cells were regulatory $T$ cells.

Conclusion: These results support the concept that $\mathrm{HO}-\mathrm{I}$ expression influences regulatory $\mathrm{T}$ cells and indicates that this mechanism is involved in the suppression of smoke induced B-cell infiltrates. The translation of this interaction to human COPD should now be pursued. 


\section{Background}

Chronic obstructive pulmonary disease (COPD) is a major global health problem with increasing morbidity and mortality. Smoking is widely accepted as the most important cause for development of the disease, still 'only' $15-20 \%$ of the smoking population eventually develops COPD [1]. COPD is characterized by a chronic inflammatory process, which ultimately leads to airway obstruction and emphysema. The important role of neutrophils, macrophages and cytotoxic T cells in its development is well established [2], yet the role of CD4 T cells and $B$ cells has only recently re-attracted attention. We and others have found oligoclonal T- and B cells in the lungs of COPD patients suggesting an antigen driven immune response $[3,4]$. These T-and B cells are aggregated in lymphoid infiltrates. Similar infiltrates have been shown in the lungs of mice chronically exposed to cigarette smoke [3]. We hypothesize that these lymphoid infiltrates contribute to the development and/or persistence of the inflammatory response in COPD [3].

Since not all patients with COPD have actively smoked, cigarette smoke cannot be the sole contributing factor in COPD development. Other factors involved are genetic factors, such as $\alpha 1$ anti-trypsin deficiency, and environmental factors, such as air pollution. Another intriguing factor that may play a role in COPD development is the 'protective' enzyme heme oxygenase- 1 (HO- 1$)$. HO- 1 is the rate limiting enzyme involved in the breakdown of heme to equimolar amounts of biliverdin, free iron and carbon monoxide (CO). HO-1 is rapidly upregulated with oxidative stress and has potent anti-inflammatory, antiapoptotic and anti-proliferative effects [5-7]. The antiinflammatory and cytoprotective effects of HO-1 are mediated by its products, of which in particular CO [810]. Notwithstanding this knowledge, the exact mechanisms behind the protective effects of $\mathrm{HO}-1$ are still poorly understood.

Interestingly, a reduced HO- 1 expression in macrophages in lung tissue and bronchoalveolar lavage (BAL) in patients with COPD has been shown $[11,12]$. In some people this may be due to a genetic polymorphism in the HO-1 promoter gene, which causes a lower HO-1 inducibility by reactive oxygen species (ROS) [13]. Additionally, adenoviral mediated HO-1 overexpression in the lung suppresses porcine pancreatic elastase induced emphysema development in mice [14], again suggesting involvement of HO-1 in emphysema development.

Our general hypothesis is that if HO-1 is insufficiently upregulated, this contributes to a higher susceptibility to noxious effects of cigarette smoke and subsequent development of COPD. We tested whether HO-1 modulation in our smoking mouse model [3] influences the develop- ment of cigarette smoke induced emphysema and lung inflammation, in particular with respect to lymphoid infiltrates. We hypothesized that HO-1 induction attenuates cigarette smoke induced emphysema and inflammation and conversely HO-1 inhibition worsens the noxious effects of cigarette smoke.

This study showed that long term HO-1 upregulation prevented the development of cigarette smoke induced B-cell infiltrates, while it had no effect on smoke induced emphysema and increase in inflammatory cells and cytokines. Increased numbers of $\mathrm{CD} 4{ }^{+} \mathrm{CD} 25^{+}$Tregs could be an explanation for the reduced presence of these B-cell infiltrates.

\section{Methods \\ Study design}

Female A/J mice were divided into six groups ( $\mathrm{n}=11$ per group); 1. Phosphate buffered saline (PBS) + smoke, 2 . Cobalt protoporphyrin (CoPP) + smoke, 3 . Tin protoporphyrin (SnPP) + smoke, 4. PBS + sham smoke, 5. CoPP + sham smoke, 6. SnPP + sham smoke. During 20 weeks the mice were subjected to protoporphyrin (or PBS) treatment and smoke (or sham smoke) exposure. After 20 weeks the mice were sacrificed, the trachea was cannulated, the right lung was ligated, and lung lobes were either snap-frozen and stored at $-80^{\circ} \mathrm{C}(\mathrm{n}=7)$ or freshly used for flow cytometry analysis $(n=7)$. The left lung was inflated, and fixed for $24 \mathrm{~h}$ with formalin with a constant pressure of $25 \mathrm{~cm} \mathrm{H}_{2} \mathrm{O}(\mathrm{n}=8)$.

Experiments were approved by the local committee on animal experimentation.

\section{Smoke exposure}

Mice were exposed to 24 puffs of cigarette smoke from two 2R1 reference cigarettes (University of Kentucky) two times per day, for 5 days a week during 20 weeks, as described previously [3].

\section{Protoporphyrin treatment}

CoPP and SnPP (Frontier Scientific, Logan, USA) were dissolved in $1 \mathrm{M} \mathrm{NaOH}$, diluted to the proper concentration with PBS and adjusted to $\mathrm{pH} 7.3-7.5$ with $\mathrm{HCl}$. The mice received a subcutaneous injection with CoPP $(25 \mu \mathrm{M} / \mathrm{kg}=$ $16.4 \mathrm{mg} / \mathrm{kg})$ every two weeks, or with SnPP $(10 \mu \mathrm{M} / \mathrm{kg}=$ $7.5 \mathrm{mg} / \mathrm{kg}$ ), or PBS weekly. These concentrations and dosing regimens were based on a pilot, in which different protoporphyrin concentrations were tested for a maximum period of two weeks.

\section{Morphometrical evaluation of emphysema}

Alveolar airspace enlargement was assessed by mean linear intercept (Lmi) by two independent individuals in a blinded manner, as described previously $[3,15]$. 


\section{Cytokines}

Frozen lung tissue was homogenized in $50 \mathrm{mM}$ Tris-HCl buffer, containing $150 \mathrm{mM} \mathrm{NaCl}$, and 0.002\% Tween-20 (pH 7.5) and centrifuged at $12000 \mathrm{~g}$ for $10 \mathrm{~min}$ to remove any insoluble material. Concentrations of TNF- $\alpha$, IL- $1 \alpha$, IL-1 $\beta$, IL-6, KC (mouse IL-8) and MCP-1 (monocyte chemoattractant protein-1) in supernatants were measured with a multiplex ELISA system (Lincoplex Systems, St Charles, MO, USA).

\section{Flow cytometry}

Single-cell leukocyte suspensions were obtained from lungs for flow cytometric analysis as described previously [16]. Numbers of $\mathrm{CD} 4{ }^{+} \mathrm{CD} 25^{+} \mathrm{T}$ cells and neutrophils were calculated based on the label combinations: CD3APC, CD4-PE, CD25-FITC and Gr1-APC. All antibodies were obtained from Pharmingen (San Diego, USA).

\section{Histology}

HO-1 expression was demonstrated with the rabbit polyclonal antibody anti-HO-1 (Stressgen, Victoria, Canada). Macrophage numbers were identified with an anti-Mac3 antibody (Pharmingen) and were quantified by morphometric analysis using Leica Qwin image analysis software (Leica Microsystems BV, Rijswijk, the Netherlands). With this computerized method the total Mac3 positive stained surface area was measured and divided by the total surface area lung tissue, and expressed as volume percentages [16]. B-cell infiltrates were detected with an anti-B220 antibody (Pharmingen). The total surface of the B220 positive infiltrates (clusters of at least 10 cells) was quantified by morphometric analysis and divided by the total surface area lung tissue, and expressed as volume percentages. Forkhead transcription factor 3 (Foxp3) expression, a marker for regulatory $\mathrm{T}$ cells, was detected in $4 \mu \mathrm{m} \mathrm{sec}-$ tions of frozen lung tissue by staining with a monoclonal anti-Foxp3 antibody (Alexis, Breda, the Netherlands). The total number of Foxp3 positive cells was counted at $25 \times$ magnification and expressed per surface area lung tissue determined by morphometric analysis. A fluorescent double staining with hamster anti mouse-CD3 (Pharmingen), followed by mouse anti hamster FITC-labeled (eBioscience) and rat anti mouse-Foxp3 (Alexis) followed by biotin conjugated goat anti rat (SBA, Birmingen, USA) and Strep-APC (Pharmingen) was performed on $4 \mu \mathrm{m}$ frozen sections of spleen and lung tissue to confirm that Foxp3 positive cells were T cells.

\section{Western blot analysis}

HO-1 protein expression was measured with western blot in whole lung homogenate (see cytokine analysis). The proteins were separated for molecular weight and blotted on a nitrocellulose membrane. The membrane was blocked overnight in 5\% skim milk and incubated with rabbit-anti-HO-1 (Stressgen) followed by a peroxidase labeled goat-anti-rabbit antibody (DakoCytomation, Heverlee, Belgium). For protein loading control the membrane was stripped using a $25 \mathrm{mM}$ Glycine-HCl buffer containing 1\% SDS (pH:2) and stained for $\beta$-actin (loading control, Abcam, Cambridge, UK) followed by a peroxidase labeled goat-anti-rabbit antibody (DakoCytomation). The bands of interest were visualized using enhanced chemiluminescence according to standard methods.

\section{Statistics}

A multiple linear regression model was used to establish importance of smoke exposure and protoporphyrin treatment and their possible interactions [17]. First, the model was tested with the effects of smoking, CoPP treatment, SnPP treatment, together with the interactions between smoking and CoPP, and smoking and SnPP. When the interactions were not significant the model was tested again without the interaction terms. Afterwards the normal distribution of the residuals was analyzed and when needed the data were log or $1 / \mathrm{x}$-transformed to normalize distributions. A significant interaction signifies that the effect of the combination is different (larger or smaller) than the addition of the separate effects of the exposures. Mann Whitney U tests were used for post-hoc analysis to test whether significant effects of CoPP and SnPP treatment were present only in smokers or sham smokers or in both groups. CD4 ${ }^{+} \mathrm{CD} 25^{+} \mathrm{T}$ cells and Foxp3 positive cells were evaluated with the Spearman correlation. A value of $\mathrm{p}<0.05$ was considered significant.

\section{Results}

Protoporphyrin treatment and smoking upregulate HO-I expression

CoPP resulted in a clear upregulation of $\mathrm{HO}-1$ protein expression in the lung, particularly in alveolar macrophages (Figure 1). Smoking also resulted in an increased HO-1 protein expression, leading to highest levels of HO1 in smoke-exposed mice that also received CoPP. SnPP resulted in a small increase in HO-1 expression, which was not affected by smoking.

\section{No effects of HO-I modulation on smoke induced emphysema development}

Smoking induced emphysema after 5.5 months smoke exposure, expressed as a significant increase in mean linear intercept (Figure 2, p < 0.01). There were no effects of both protoporphyrins on the mean linear intercept.

\section{Smoking increases the levels of inflammatory cytokines in lung tissue}

Smoking significantly increased the levels of the pro inflammatory cytokines TNF- $\alpha$, IL- $1 \alpha$, IL- $1 \beta$, IL- $6, \mathrm{KC}$, and MCP-1 in lung homogenate (Figure 3, $\mathrm{p}<0.01$ ). CoPP increased the levels of IL- 6 and KC. Levels of IL- 6 were sig- 
A

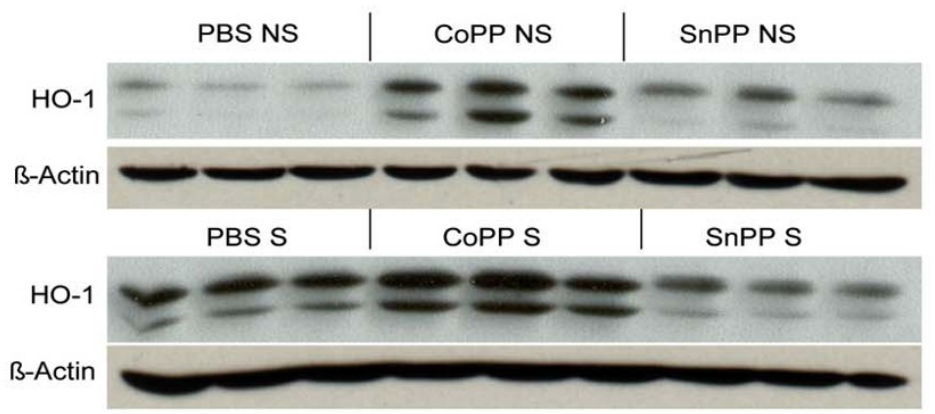

B

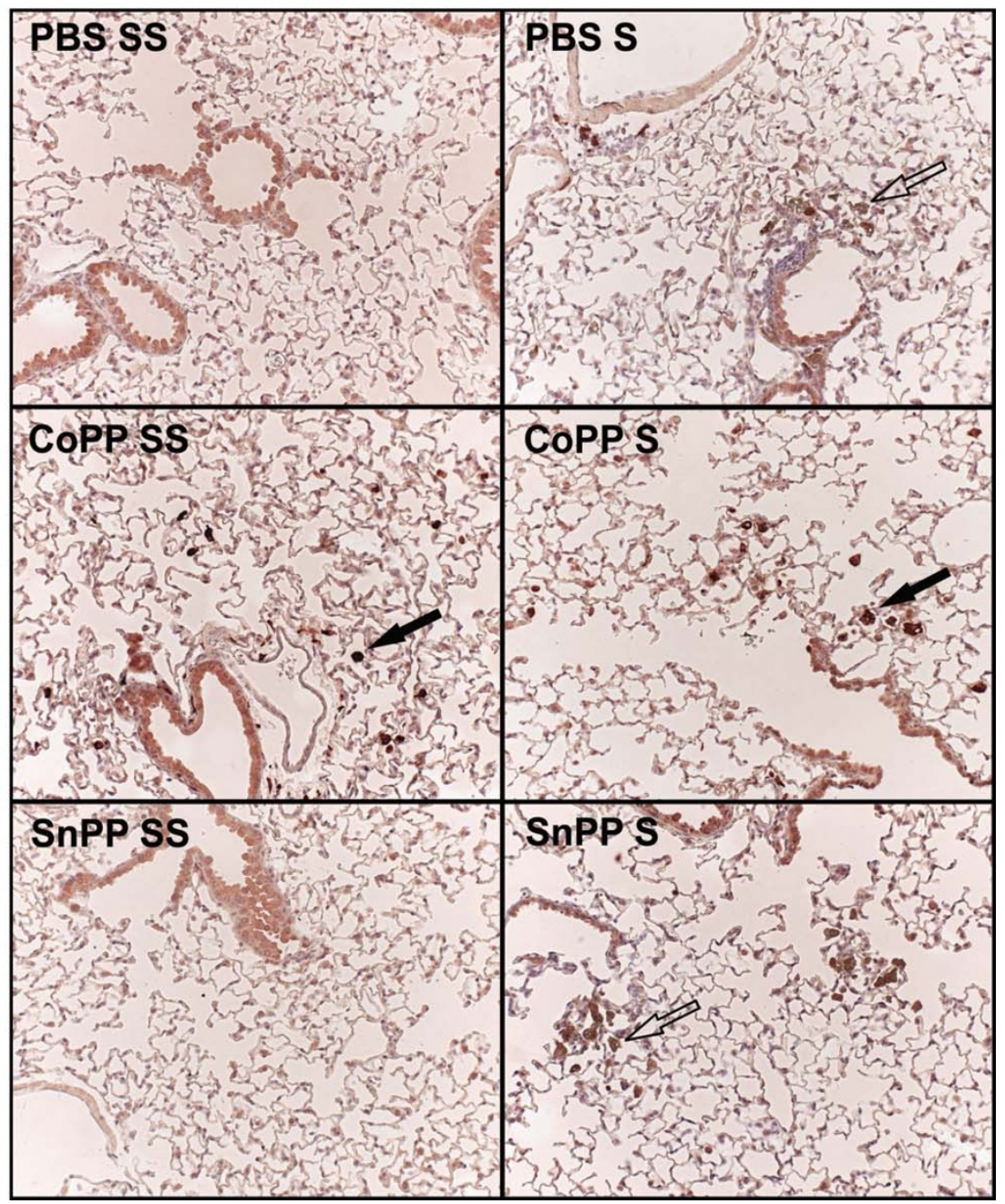

Figure I

HO-I protein expression. A: Protein bands for HO-I (above band) and $\beta$-actin (loading control) detected by western blot analysis after long term smoke exposure and protoporphyrin treatment. Three animals per group are shown. B: A representative picture of the HO-I expression (dark red) in lung tissue is shown for each group (25×). Particularly, alveolar macrophages (indicated with a closed arrow) show an increased HO-I expression after CoPP treatment. The epithelium stains faintly in all groups and no differences were observed between the groups. The brown cells (indicated with an open arrow) are pigmented macrophages, a result of the smoke exposure. S: smoke, SS: Sham smoke. Mice were divided into 6 groups; I. Phosphate buffered saline $(\mathrm{PBS})+$ smoke, 2 . Cobalt protoporphyrin (CoPP) + smoke, 3. Tin protoporphyrin $(\mathrm{SnPP})+$ smoke, 4 . PBS + sham smoke, 5. CoPP + sham smoke, 6. SnPP + sham smoke. 


\section{Emphysema development}

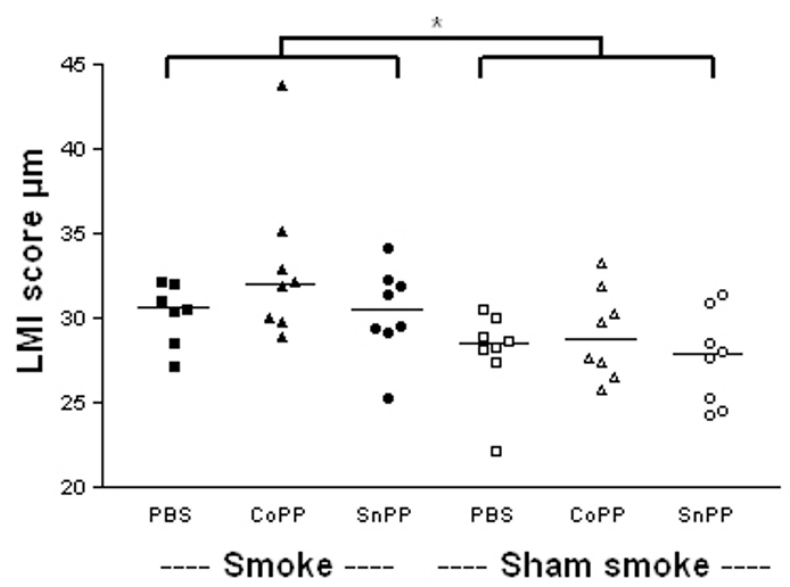

Figure 2

Emphysema development. Mean linear intercept (LMI) after long term smoke exposure and protoporphyrin treatment. Smoke groups are represented by closed symbols and sham smoke groups by open symbols. * indicates a significant effect of smoke exposure $(p<0.05)$. There were no interactions and no effects of CoPP or SnPP treatment.

nificantly increased after CoPP only in the sham smokers (PBS sham smoke vs. CoPP sham smoke p <0.05). KC levels were increased after CoPP in both smokers and sham smokers (PBS sham smoke vs. CoPP sham smoke and PBS smoke vs. CoPP smoke $\mathrm{p}<0.01)$. In contrast, SnPP reduced the levels of TNF- $\alpha$, IL- $1 \alpha$, IL-1 $\beta$, KC and MCP-1. Levels of these cytokines were significantly decreased after SnPP in the sham smokers only (PBS sham smoke vs. SnPP sham smoke $\mathrm{p}<0.05)$. Additionally, there was a positive interaction between SnPP and smoking for KC ( $\mathrm{p}$ $<0.01$ ) leading to higher KC levels in the SnPP smokers compared to the SnPP sham smokers.

\section{Smoking increases neutrophils and macrophages in lung tissue}

Smoking increased the numbers of neutrophils and macrophages in the lung (Figure $4, \mathrm{p}<0.01$ ). There were no effects of both protoporphyrins on the numbers of neutrophils and macrophages.

\section{CoPP treatment prevents cigarette smoke induced B-cell infiltrates}

Smoking significantly increased the number of B-cell infiltrates in lung tissue (Figure 5, $\mathrm{p}<0.01$ ). In addition, there was a significant negative interaction between smoking and CoPP $(\mathrm{p}<0.01)$ signifying that the smoke induced increase in B-cell infiltrates was reduced in the smokeexposed mice that also received CoPP (CoPP smokers).

\section{Reduced number of B-cell infiltrates in CoPP smokers is accompanied by increased numbers of $C D 4^{+} \mathrm{CD} 25^{+} \mathrm{T}$ cells in lung homogenate}

Smoking significantly increased the numbers of $\mathrm{CD} 4{ }^{+} \mathrm{CD} 25^{+} \mathrm{T}$ cells in lung homogenate (Figure 6A, $\mathrm{p}<$ $0.01)$. Additionally, there was a significant positive interaction between smoking and CoPP treatment for the numbers of CD $4{ }^{+} \mathrm{CD} 25^{+} \mathrm{T}$ cells $(\mathrm{p}<0.05)$, signifying that the increase of smoking was larger in combination with CoPP, resulting in the highest numbers of $\mathrm{CD} 4{ }^{+} \mathrm{CD} 25^{+} \mathrm{T}$ cells in the CoPP smokers. This higher expression of CD25 in the CD4+T-cell population of CoPP smoking compared to PBS smoking mice is illustrated in Figure 6B.

\section{The increase in $C D 4^{+} C D 25^{+} T$ cells represents an increase in regulatory $T$ cells}

To investigate whether the increased number of $\mathrm{CD} 4{ }^{+} \mathrm{CD} 25^{+} \mathrm{T}$ cells in the CoPP smokers represented an increase in regulatory $\mathrm{T}$ cells (Tregs), we stained lung tissue for the Treg specific marker Foxp3 (Figure 7A). Smoking significantly increased the numbers of Foxp 3 positive cells in lung tissue (Figure $7 \mathrm{~B}, \mathrm{p}<0.01)$ with a trend $(\mathrm{p}=$ 0.07) for a similar effect of CoPP on the number of Foxp3 positive cells. Double staining for CD3 and Foxp3 in lung and spleen tissue (Figure 7C) showed that Foxp3 positive cells were indeed T cells. Furthermore, the number of Foxp3 positive cells in lung tissue correlated positively with the number of CD4 ${ }^{+} \mathrm{CD} 25^{+} \mathrm{T}$ cells in lung homogenate $(\rho=0.7, \mathrm{p}<0.01)$.

\section{Discussion}

In this study we showed that $\mathrm{HO}-1$ protein upregulation by CoPP treatment reduced the number of cigarette smoke induced B-cell infiltrates in mice. These B-cell infiltrates were similar to the lymphoid follicles found in COPD patients [3] and are suggested to contribute to COPD development. The reduced number of B-cell infiltrates in the CoPP smokers was accompanied by increased numbers of $\mathrm{CD} 4{ }^{+} \mathrm{CD} 25^{+} \mathrm{T}$ cells, which most likely are Tregs. In contrast to our hypothesis, HO-1 upregulation had no protective effect on cigarette smoke induced increases in other inflammatory cells and inflammatory cytokines and subsequent emphysema development. Additionally, SnPP treatment did not aggravate smoke induced damage.

We succeeded in long term HO-1 protein upregulation in our smoking mouse model and to our knowledge this is the first study using an intervention that leads to long term HO-1 protein upregulation in vivo. Given the importance of macrophages and epithelium in the production of inflammatory mediators after an inflammatory or oxidative stimulus, these cells were carefully evaluated for their HO-1 expression. In both in vitro and in vivo studies oxidative stress and cigarette smoke have been shown to 

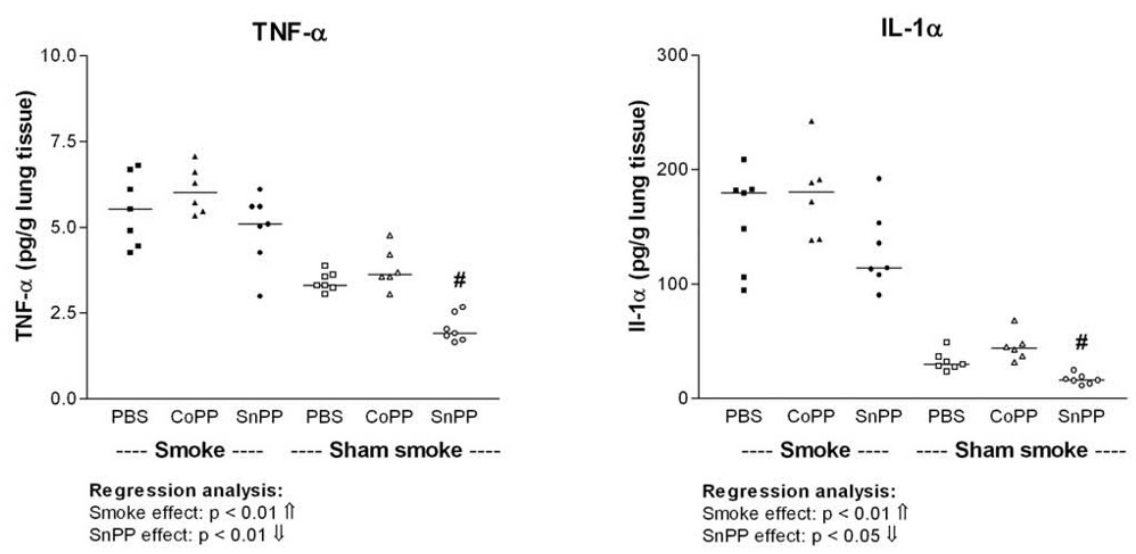

Regression analysis:

Smoke effect: $p<0.01 \Uparrow$

SnPP effect: $p<0.05 \Downarrow$

IL-1 $\beta$
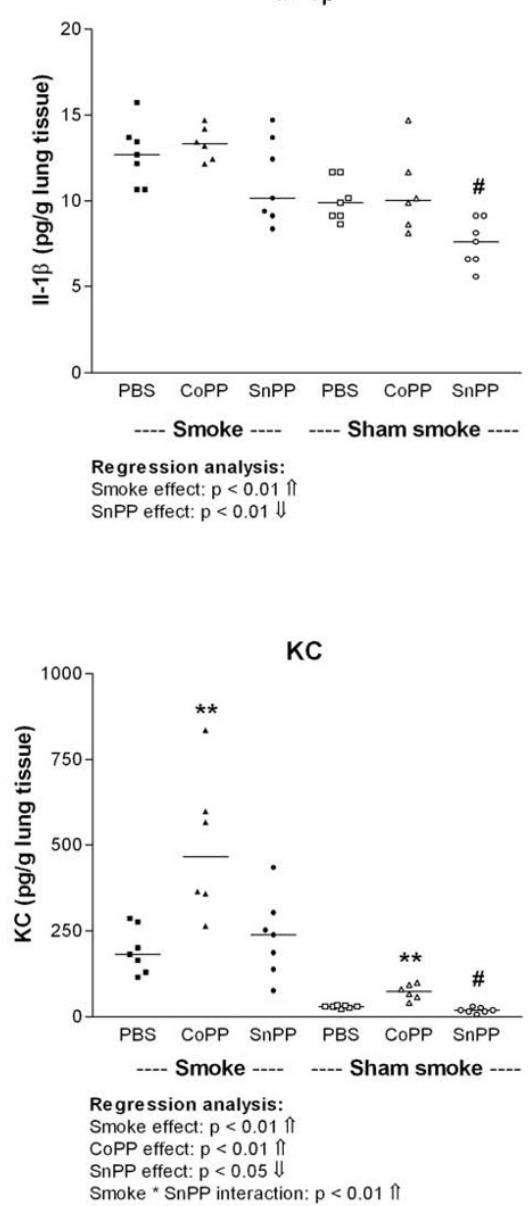

IL-6

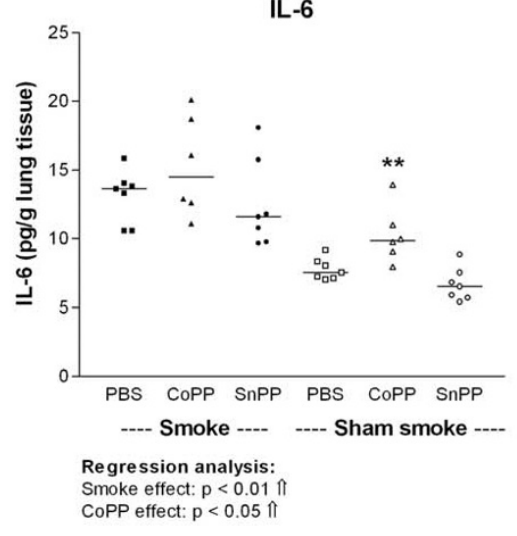

MCP-1

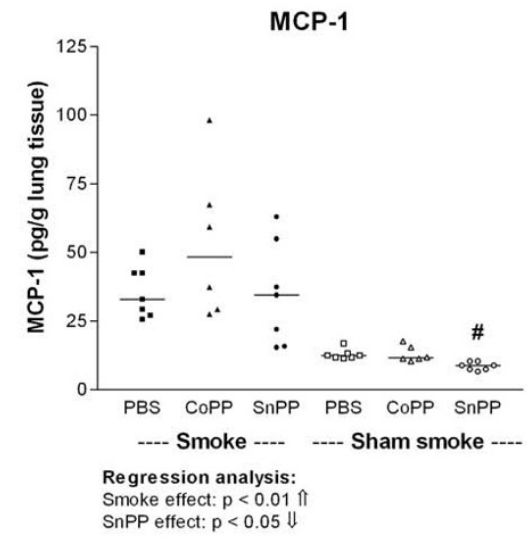

Figure 3

Inflammatory cytokines in lung homogenate. TNF- $\alpha$, IL-I $\alpha$, IL-I $\beta, \mathrm{IL}-6, \mathrm{KC}$ and MCP-I levels expressed as pg/g lung homogenate after long term smoke exposure and protoporphyrin treatment. Smoke groups are represented by closed symbols and sham smoke groups by open symbols. The significant results of the regression analysis are depicted beneath the figures. \# indicates a significant effect of SnPP treatment (SnPP vs. PBS, post-hoc analysis), and ** indicates a significant effect of CoPP treatment (CoPP vs. PBS, post-hoc analysis) $(\mathrm{P}<0.05)$. 


\section{Neutrophils}

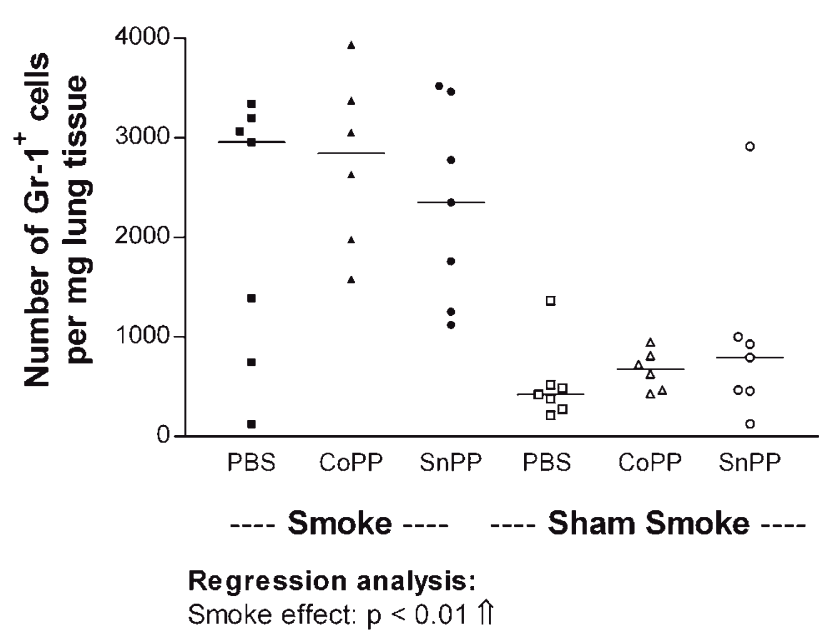

Macrophages

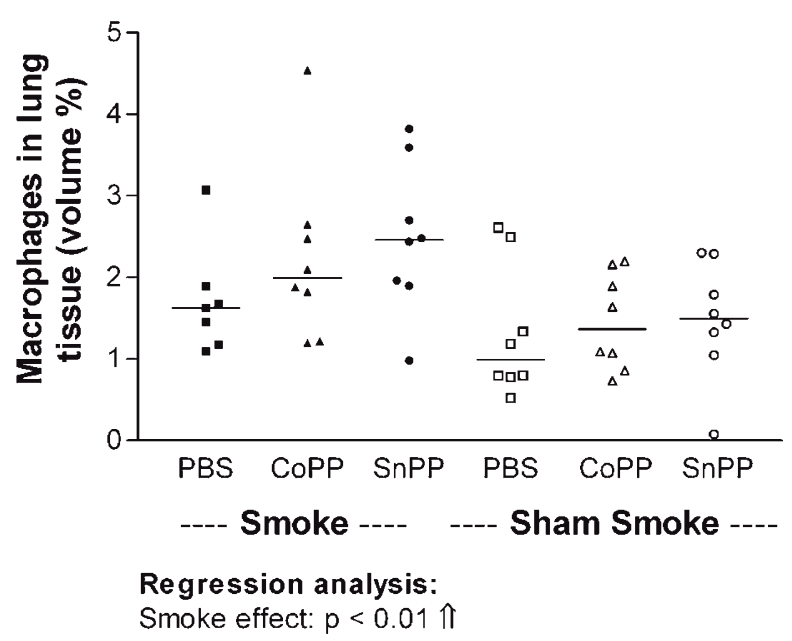

\begin{abstract}
Figure 4
Inflammatory cells in lung tissue. Neutrophils and macrophages expressed in lung tissue after long term smoke exposure and protoporphyrin treatment. Neutrophils are expressed as numbers per mg lung homogenate. Macrophages are expressed as volume percentages. Smoke groups are represented by closed symbols and sham smoke groups by open symbols. The significant results of the regression analysis are depicted beneath the figures.
\end{abstract}

induce HO-1 expression in pulmonary epithelial cells and alveolar macrophages [18-21]. Furthermore, HO-1 overexpression in epithelial cells is protective against oxidative stress [22]. Indeed, our study showed an increased HO-1 expression after both cigarette smoke exposure and CoPP treatment. This increased HO-1 expression was highest in CoPP treated smoking mice and particularly seen in alveolar macrophages yet not in epithelial cells. Unfortunately, HO-1 upregulation provided no protective effects against the smoke induced increases in inflammatory cells and cytokines, nor did it protect against smoke induced emphysema. These results do not fit with our hypothesis, but might be explained in several ways. Firstly, the epithelium did not show an increased HO-1 expression after CoPP treatment, which still makes it possible for these cells to respond to cigarette smoke by producing inflammatory mediators. In fact, the majority of the inflammatory cytokines that were increased after smoke exposure in our study can be produced by epithelial cells in response to cigarette smoke [23-26], which supports this option. Secondly, contrary to what we had expected, the levels of IL-6 and KC increased after CoPP treatment in lung tissue, which may suggest some toxicity of the long term dosing of CoPP. Given the fact that the majority of the mice showed irritation of the skin at the injection site after approximately 4 months of CoPP treatment, the CoPP dose indeed might have been too high. It is also conceivable that long term exposure to CoPP, much longer than performed by others, might have other unexpected effects. For future long term experiments it is probably more appropriate to use HO-1 transgenic mice, or use less toxic downstream products of the HO-1 system e.g. $\mathrm{CO}$ or bilirubin. Finally, it was not possible to reliably measure $\mathrm{HO}$-activity levels on the frozen material available in this study; a sufficiently sensitive assessment of HO-activity should certainly be included in future experiments.

SnPP treatment resulted in a slightly increased HO-1 protein expression, which was not affected by smoke exposure. In contrast to our hypothesis, SnPP treatment did not aggravate the damaging effects of smoke exposure, but did decrease the levels of several inflammatory cytokines. SnPP is known to inhibit the HO-1 activity, while it increases HO-1 protein expression [27], which supports the increased HO- 1 expression after SnPP treatment in our study. For SnPP treatment both inflammatory and antiinflammatory effects have been described [28-31]. Antiinflammatory effects were shown while the HO-1 protein level was increased but the HO-1 activity downregulated, suggesting that HO-1 induction by SnPP can have antiinflammatory and anti-apoptotic effects independently of the HO-1 enzyme activity [30,31]. 
A

\section{B-cell infiltrates in lung tissue}

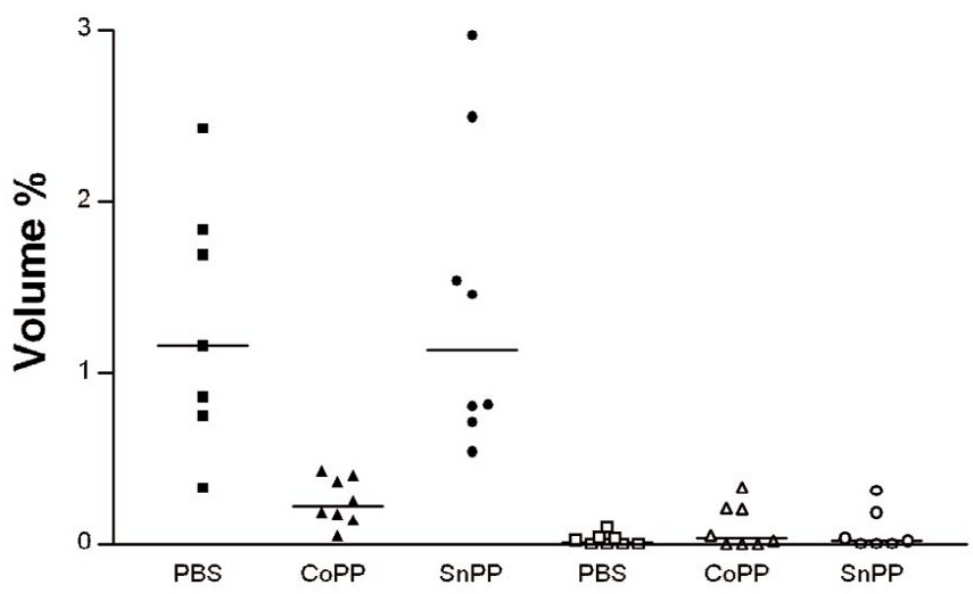

---- Smoke ---- ---- Sham smoke ----

Regression analysis:

Smoke effect: $p<0.01 \Uparrow$

Smoke * CoPP interaction: $p<0.01 \Downarrow$

B

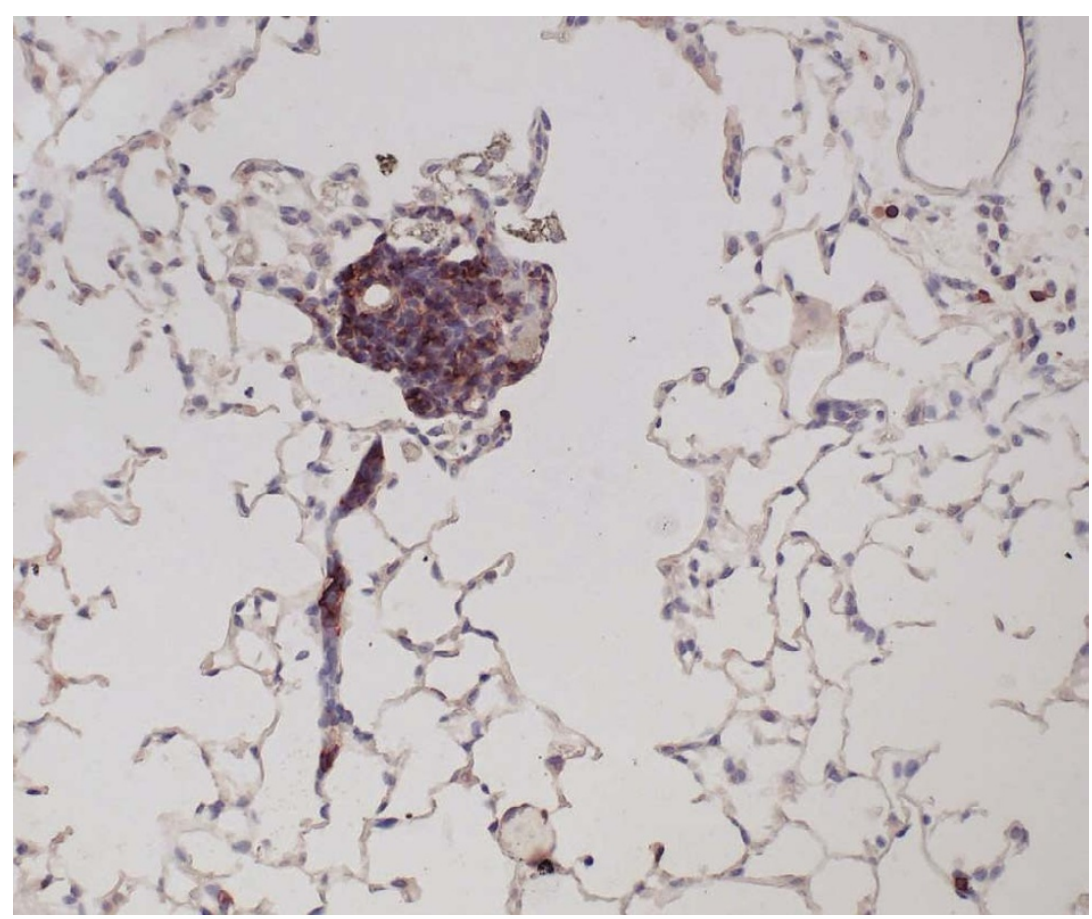

Figure 5

B-cell infiltrates in lung tissue. A: Volume percentage of B220 positive infiltrates after long term smoke exposure and protoporphyrin treatment. Smoke groups are represented by closed symbols and sham smoke groups by open symbols. The significant results of the regression analysis are depicted beneath the figure. B: Example of a B-cell infiltrate positive for B220 (red) present in lung tissue $(50 x)$. 
A

$\mathrm{CD}^{+} \mathrm{CD}^{+} 5^{+} \mathrm{T}$ cells in lung tissue

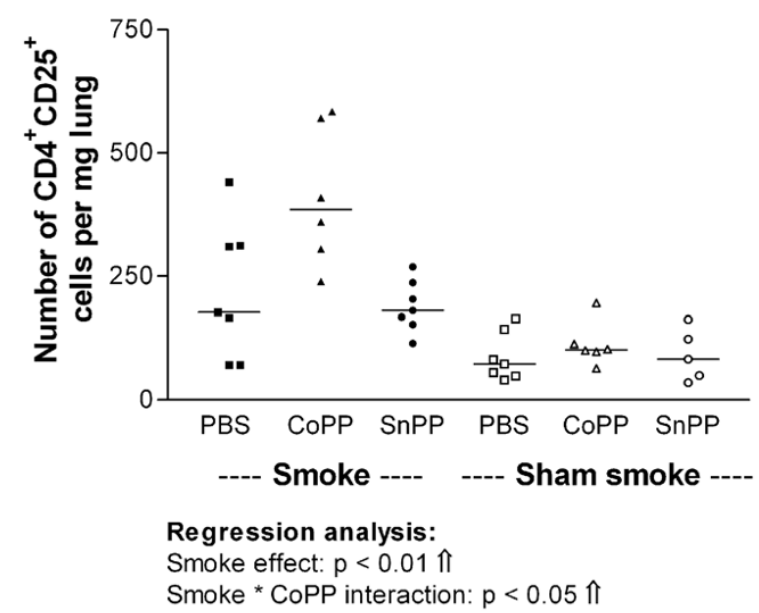

B
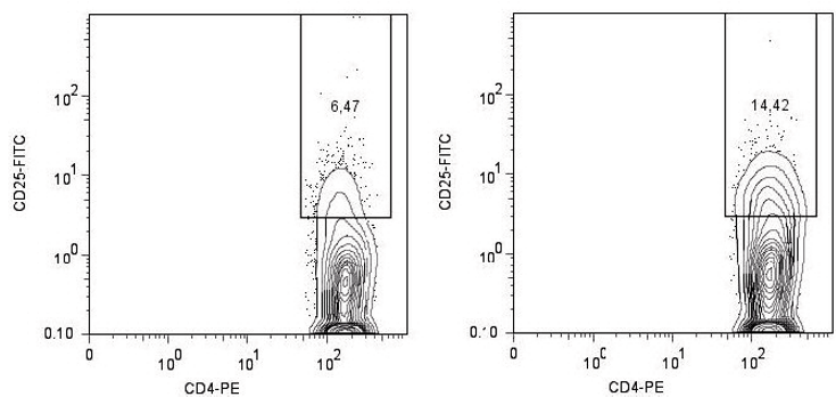

Figure 6

$\mathrm{CD}^{+} \mathrm{CD}^{+} 5^{+} \mathbf{T}$ cells in lung tissue. A: $\mathrm{CD}^{+} \mathrm{CD} 25^{+} \mathrm{T}$ cells expressed as numbers per $\mathrm{mg}$ lung tissue after long term smoke exposure and protoporphyrin treatment. Smoke groups are represented by closed symbols and sham smoke groups by open symbols. The significant results of the regression analysis are depicted beneath the figure. B: Example of the flow cytometry analysis: The percentage of CD25 positive cells within the $C D 4^{+} \mathrm{T}$ cell population is shown for a PBS (left) and a CoPP (right) smoking mouse.

The most important finding of this study was the protective effect of HO-1 upregulation on the development of cigarette smoke induced $\mathrm{B}$-cell infiltrates, leading to reduced numbers of B-cell infiltrates in CoPP treated smoking mice. The B-cell infiltrates consisted mainly of B cells surrounded by $\mathrm{T}$ cells and were comparable to the Bcell follicles found in patients with COPD [3]. B cells in these follicles were found to be oligoclonal in nature [3], suggesting an antigen driven immune response. Whether the inflammatory response in COPD is a true antigen specific response is not fully proven, nor is it clear which antigen(s) may be involved. We consider matrix degradation products, microbial components, and cigarette smoke constituents as possible candidates. We hypothesize that these lymphoid infiltrates contribute to the development and/or persistence of the inflammatory response in COPD. This study showed that reduced numbers of B-cell infiltrates did not prevent smoke induced emphysema development, which suggests that the presence of B-cell infiltrates may not be a mandatory prerequisite for emphysema development in this model. This is compatible with the results of d'Hulst et al, showing smoke induced emphysema development in scid mice, lacking functional B- and T-cells [32]. To what extent B cells contribute to the persistence of the inflammatory response in COPD remains unclear. However, since these mouse models of cigarette smoke induced emphysema resemble mild disease, it is also possible that B cells might be more important in severe than in mild disease. This would be supported by the data of Hogg et al who found B-cells especially in GOLD stage 3 and 4 [33].

In this study we extended our previous observations on Bcell infiltrates [3] by the intriguing finding that the reduced number of B-cell infiltrates was accompanied by increased numbers of $\mathrm{CD} 4{ }^{+} \mathrm{CD} 25^{+} \mathrm{T}$ cells in the CoPP smokers. The $\mathrm{CD} 4^{+} \mathrm{CD} 25^{+} \mathrm{T}$-cell population consists of a mixture of activated $\mathrm{T}$ cells and Tregs. Tregs are important in controlling immunological tolerance and preventing auto-immune reactions by inhibiting T-cell responses [34,35]. Dysfunction of Tregs can lead to auto-immune diseases, allergy, and chronic inflammatory diseases. The currently best described subset of Tregs is that of the naturally occurring Tregs, expressing high levels of CD25 and the transcription factor Foxp3 [34].

In this study, the number of CD4 ${ }^{+} \mathrm{CD} 25^{+} \mathrm{T}$ cells correlated positively with the number of Foxp3 positive cells and the highest numbers of Foxp3 positive cells were present in the CoPP smokers with a trend for an effect of CoPP treatment. Together, this suggests that the increase in $\mathrm{CD} 4{ }^{+} \mathrm{CD} 25^{+} \mathrm{T}$ cells in the CoPP smokers represents an increase in Tregs.

Interestingly, a direct link between Foxp3 and HO-1 expression and function of Tregs was reported recently; both Foxp3 and HO-1 were shown to be expressed in Tregs and the suppressive effects of Tregs were shown to be mediated by HO-1 expression [36]. Furthermore, in a model of allergic airway inflammation, $\mathrm{HO}-1$ upregulation was shown to increase Treg numbers and their suppressive capacity [37].

Next to their effects on T cells, Tregs can also directly suppress B-cell responses without having to suppress the adjacent $\mathrm{T}$ cells $[38,39]$. This proves that activated $\mathrm{T}$ cells are not the only target for Tregs and that Tregs can also be involved in the reduced presence of B-cell infiltrates. Inter- 
A

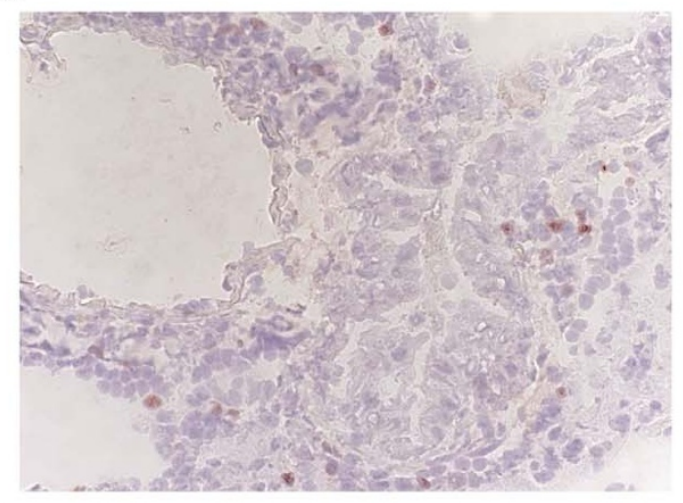

B

Foxp3 positive cells in lung tissue

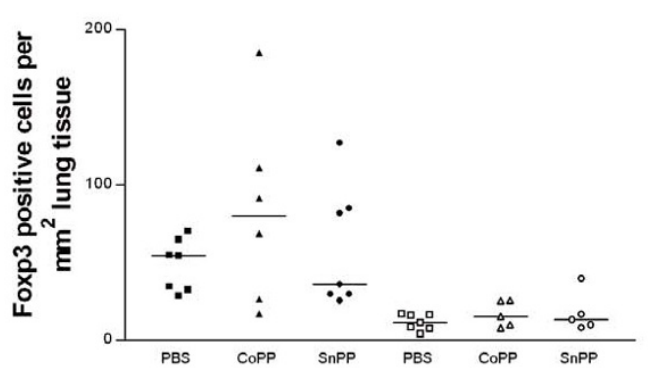

---- Smoke ---- ---- Sham smoke ----

Regression analysis:

Smoke effect: $p<0.01 \Uparrow$

CoPP effect: $p=0.07 \Uparrow$
C
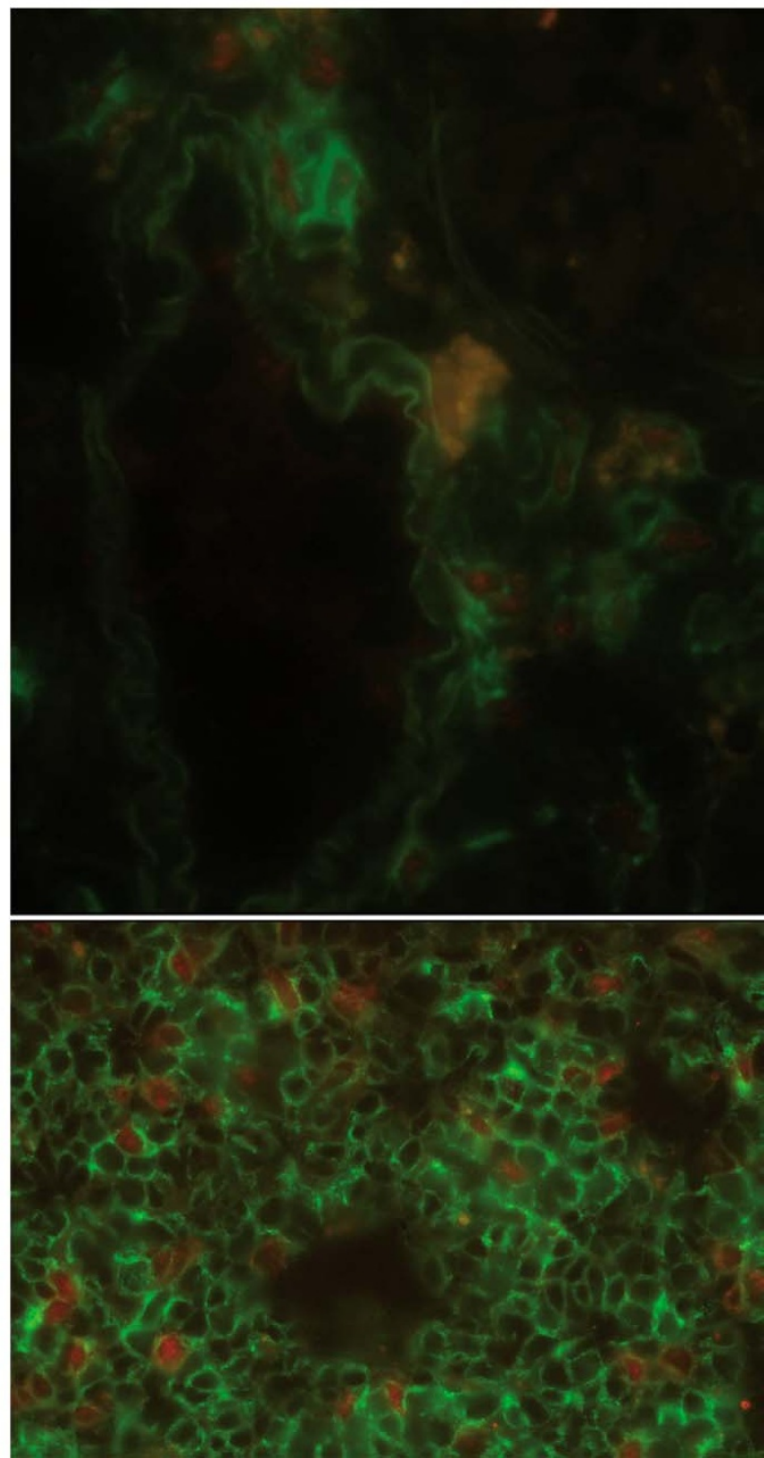

\section{Figure 7}

Foxp3 positive cells in lung tissue. A: Foxp3 positive cells (red nuclear staining) present in lung tissue (100x). B: Foxp3 positive cells expressed as total numbers per $\mathrm{mm}^{2}$ lung tissue after long term smoke exposure and protoporphyrin treatment. Smoke groups are represented by closed symbols and sham smoke groups by open symbols. The significant results of the regression analysis are depicted beneath the figure, as well as a trend for an effect of CoPP treatment. C: Fluorescent double staining for CD3 (green) and Foxp3 (red) in lung (upper panel, 630x) and spleen (lower panel, 400x) showing that Foxp3 specifically stains $T$ cells. The orange cells in the lung are pigmented macrophages, which show auto fluorescence.

estingly, chronic cigarette smoke exposure was shown to increase the numbers of Tregs in the airways of healthy smokers and smokers with COPD [40], whereas decreased Treg numbers were found in lung tissue of emphysema patients [41]. Additionally, we found high numbers of Foxp3 positive cells present in and surrounding B cell follicles in the lungs of COPD patients (unpublished results).
Altogether, these findings suggest a role for Tregs in COPD in the smoke induced inflammatory response, and possibly also B-cell follicle formation, and support the idea that the HO-1 protein upregulation affected the Treg population in our model thereby possibly contributing to the observed reduced presence of B-cell infiltrates. 


\section{Conclusion}

Long term HO-1 upregulation prevented the development of cigarette smoke induced B-cell infiltrates, while it had no effect on smoke induced emphysema and increase in neutrophils and macrophages and inflammatory cytokines. A possible explanation for this effect of $\mathrm{HO}-1$ upregulation on presence of B-cell infiltrates is the increased presence of $\mathrm{CD} 4{ }^{+} \mathrm{CD} 25^{+}$Tregs. The exact role of these Tregs in the smoke induced inflammatory response has to be elucidated and the translation to human COPD should now be pursued.

\section{Competing interests}

The author(s) declare that they have no competing interests.

\section{Authors' contributions}

CB performed the animal experiments, analyzed the data, performed statistical analysis and drafted the manuscript. $\mathrm{MH}$ participated in the study design and data analysis, and helped to draft the manuscript. BS participated in the study design and coordinated and performed the animal experiments. ML and MG carried out the flow cytometric, cytokine and immunohistochemical analyses. WT, DP and DS were involved in the study design and critically reviewed the manuscript. HK participated in the study design, was supervisor of the experiments, and helped with the statistical analyses and writing of the manuscript. All authors read and approved the final manuscript.

\section{Acknowledgements}

The authors thank Nicole Stowell, Anuk Das, and Don Griswold (Centocor, PA, USA) for performing the Luminex assays, Pieter Klok and Mieke Versluis for their assistance with sacrificing the mice and the colleagues from the Central Animal Facility for performing the smoke exposures.

This work was supported by a Spinoza premium of the Dutch Government (Prof. Dr. D.S. Postma) and the Groningen University Institute for Drug Exploration (GUIDE).

\section{References}

I. National Heart $L$ and Blood Institute, Organization WH: Global Strategy for Diagnosis, Management, and Prevention of Chronic Obstructive Pulmonary Disease: NHLBI/WHO Workshop report, update 2005. 2005.

2. Barnes PJ, Shapiro SD, Pauwels RA: Chronic obstructive pulmonary disease: molecular and cellular mechanisms. Eur Respir J 2003, 22:672-688.

3. van der Strate BW, Postma DS, Brandsma CA, Melgert BN, Luinge MA, Geerlings M, Hylkema MN, van den Berg A, Timens W, Kerstjens HA: Cigarette Smoke-induced Emphysema: A Role for the B Cell? Am J Respir Crit Care Med 2006, 173:75I-758.

4. Sullivan AK, Simonian PL, Falta MT, Mitchell JD, Cosgrove GP, Brown KK, Kotzin BL, Voelkel NF, Fontenot AP: Oligoclonal CD4+ T cells in the lungs of patients with severe emphysema. Am J Respir Crit Care Med 2005, 172:590-596.

5. Choi AM, Alam J: Heme oxygenase-I: function, regulation, and implication of a novel stress-inducible protein in oxidantinduced lung injury. Am J Respir Cell Mol Biol 1996, 15:9-19.

6. Otterbein LE, Choi AM: Heme oxygenase: colors of defense against cellular stress. Am J Physiol Lung Cell Mol Physiol 2000, 279:LI029-LI037.
7. Otterbein LE, Soares MP, Yamashita K, Bach FH: Heme oxygenaseI: unleashing the protective properties of heme. Trends Immunol 2003, 24:449-455.

8. Otterbein LE, Bach FH, Alam J, Soares M, Tao Lu H, Wysk M, Davis RJ, Flavell RA, Choi AM: Carbon monoxide has anti-inflammatory effects involving the mitogen-activated protein kinase pathway. Nat Med 2000, 6:422-428.

9. Slebos DJ, Ryter SW, Choi AM: Heme oxygenase-I and carbon monoxide in pulmonary medicine. Respir Res 2003, 4:7.

10. Song R, Kubo M, Morse D, Zhou Z, Zhang X, Dauber JH, Fabisiak J, Alber SM, Watkins SC, Zuckerbraun BS, Otterbein LE, Ning W, Oury TD, Lee PJ, McCurry KR, Choi AMK: Carbon Monoxide Induces Cytoprotection in Rat Orthotopic Lung Transplantation via Anti-Inflammatory and Anti-Apoptotic Effects. Am J Pathol 2003, 163:231.

II. Maestrelli P, Paska C, Saetta M: Decreased haem oxygenase-I and increased inducible nitric oxide synthase in the lung of severe COPD patients. Eur Respir J 2003, 2 I:97I-976.

12. Slebos DJ, Kerstjens HA, Rutgers SR, Kauffman HF, Choi AM, Postma DS: Haem oxygenase-I expression is diminished in alveolar macrophages of patients with COPD. Eur Respir J 2004, 23:652-653.

13. Yamada N, Yamaya M, Okinaga S, Nakayama K, Sekizawa K, Shibahara $\mathrm{S}$, Sasaki $\mathrm{H}$ : Microsatellite polymorphism in the heme oxygenase-I gene promoter is associated with susceptibility to emphysema. Am J Hum Genet 2000, 66:187-195.

14. Shinohara T, Kaneko T, Nagashima Y, Ueda A, Tagawa A, Ishigatsubo $Y$ : Adenovirus-mediated transfer and overexpression of heme oxygenase I cDNA in lungs attenuates elastaseinduced pulmonary emphysema in mice. Hum Gene Ther 2005, 16:318-327.

15. Thurlbeck WM: Measurement of pulmonary emphysema. Am Rev Respir Dis 1967, 95:752-764.

16. Hylkema MN, Hoekstra MO, Luinge M, Timens W: The strength of the OVA-induced airway inflammation in rats is strain dependent. Clin Exp Immunol 2002, 1 29:390-396.

17. Altman DG: Practical statistics for medical research London, Chapman \& Hall; | 991 .

18. Fukano $Y$, Yoshimura H, Yoshida T: Heme oxygenase-I gene expression in human alveolar epithelial cells (A549) following exposure to whole cigarette smoke on a direct in vitro exposure system. Exp Toxicol Pathol 2006, 57:4II I-4I8.

19. Fukano Y, Oishi M, Chibana F, Numazawa S, Yoshida T: Analysis of the expression of heme oxygenase-I gene in human alveolar epithelial cells exposed to cigarette smoke condensate. J Toxicol Sci 2006, 31 1:99-109.

20. lles KE, Dickinson DA, Wigley AF, Welty NE, Blank V, Forman HJ: HNE increases HO-I through activation of the ERK pathway in pulmonary epithelial cells. Free Radic Biol Med 2005, 39:355-364.

21. Maestrelli P, El Messlemani AH, De Fina O, Nowicki Y, Saetta M, Mapp C, Fabbri LM: Increased expression of heme oxygenase (HO)-I in alveolar spaces and $\mathrm{HO}-2$ in alveolar walls of smokers. Am J Respir Crit Care Med 200I, 164:1508-15I3.

22. Lee PJ, Alam J, Wiegand GW, Choi AM: Overexpression of heme oxygenase- $I$ in human pulmonary epithelial cells results in cell growth arrest and increased resistance to hyperoxia. Proc Natl Acad Sci U S A 1996, 93:10393-10398.

23. Reynolds PR, Cosio MG, Hoidal JR: Cigarette smoke-induced Egr-I upregulates proinflammatory cytokines in pulmonary epithelial cells. Am J Respir Cell Mol Biol 2006, 35:3 I4-3।9.

24. Rusznak C, Mills PR, Devalia JL, Sapsford RJ, Davies RJ, Lozewicz S: Effect of cigarette smoke on the permeability and IL-I beta and sICAM-I release from cultured human bronchial epithelial cells of never-smokers, smokers, and patients with chronic obstructive pulmonary disease. Am J Respir Cell Mol Biol 2000, 23:530-536.

25. Masubuchi T, Koyama S, Sato E, Takamizawa A, Kubo K, Sekiguchi M, Nagai S, Izumi T: Smoke extract stimulates lung epithelial cells to release neutrophil and monocyte chemotactic activity. Am J Pathol 1998, I 53:1903-1912.

26. Wyatt TA, Heires AJ, Sanderson SD, Floreani AA: Protein kinase $\mathbf{C}$ activation is required for cigarette smoke-enhanced $\mathrm{C5a}$ mediated release of interleukin-8 in human bronchial epithelial cells. Am J Respir Cell Mol Biol 1999, 21:283-288. 
27. Sardana MK, Kappas A: Dual control mechanism for heme oxygenase: tin(IV)-protoporphyrin potently inhibits enzyme activity while markedly increasing content of enzyme protein in liver. Proc Natl Acad Sci U S A 1987, 84:2464-2468.

28. Sass G, Soares MPY K., Tiegs G: Heme Oxygenase-I and Its Reaction Product, Carbon Monoxide, Prevent Inflammation-Related Apoptotic Liver Damage in Mice. Hepatology 2003, 38:909-918.

29. Huang TY, Tsai PS, Wang TY, Huang CL, Huang C): Hyperbaric oxygen attenuation of lipopolysaccharide-induced acute lung injury involves heme oxygenase-I. Acta Anaesthesiol Scand 2005, 49: $1293-1301$

30. Kaizu T, Tamaki T, Tanaka M, Uchida Y, Tsuchihashi S, Kawamura A, Kakita A: Preconditioning with tin-protoporphyrin IX attenuates ischemia/reperfusion injury in the rat kidney. Kidney Int 2003, 63: 1393-1403.

31. Uchida Y, Tamaki T, Tanaka M, Kaizu T, Tsuchihashi S, Takahashi T, Kawamura A, Kakita A: Induction of specific stress response increases resistance of rat liver allografts to cold ischemia and reperfusion injury. Transpl Int 2003, 16:396-404.

32. D'hulst Al, Maes T, Bracke KR, Demedts IK, Tournoy KG, Joos GF, Brusselle GG: Cigarette smoke-induced pulmonary emphysema in scid-mice. Is the acquired immune system required? Respir Res 2005, 6:147.

33. Hogg JC, Chu F, Utokaparch S, Woods R, Elliott WM, Buzatu L, Cherniack RM, Rogers RM, Sciurba FC, Coxson HO, Pare PD: The nature of small-airway obstruction in chronic obstructive pulmonary disease. N Engl J Med 2004, 350:2645-2653.

34. Sakaguchi S: Naturally arising Foxp3-expressing CD25+CD4+ regulatory $T$ cells in immunological tolerance to self and non-self. Nat Immunol 2005, 6:345-352.

35. Bacchetta R, Gregori S, Roncarolo MG: CD4+ regulatory T cells: mechanisms of induction and effector function. Autoimmun Rev 2005, 4:49I-496.

36. Choi BM, Pae HO, Jeong YR, Kim YM, Chung HT: Critical role of heme oxygenase- $I$ in Foxp3-mediated immune suppression. Biochem Biophys Res Commun 2005, 327: 1066-107I.

37. Xia ZW, Zhong WW, Xu LQ, Sun JL, Shen QX, Wang JG, Shao J, Li YZ, Yu SC: Heme oxygenase-I-mediated CD4+CD25high regulatory $\mathbf{T}$ cells suppress allergic airway inflammation. J Immunol 2006, I77:5936-5945.

38. Lim HW, Hillsamer P, Banham AH, Kim CH: Cutting edge: direct suppression of $B$ cells by CD4+ CD25+ regulatory $T$ cells. J Immunol 2005, I75:4I80-4I83.

39. Lim HW, Hillsamer P, Kim CH: Regulatory T cells can migrate to follicles upon $\mathbf{T}$ cell activation and suppress $\mathbf{G C}$-Th cells and GC-Th cell-driven B cell responses. J Clin Invest 2004, I I 4:1640-1649.

40. Smyth LJ, Starkey C, Vestbo J, Singh D: CD4-regulatory cells in COPD patients. Chest 2007, I32:156-163.

4I. Lee SH, Goswami S, Grudo A, Song LZ, Bandi V, Goodnight-White S, Green L, Hacken-Bitar J, Huh J, Bakaeen F, Coxson HO, Cogswell S, Storness-Bliss C, Corry DB, Kheradmand F: Antielastin autoimmunity in tobacco smoking-induced emphysema. Nat Med 2007, 13:567-569.
Publish with Bio Med Central and every scientist can read your work free of charge

"BioMed Central will be the most significant development for disseminating the results of biomedical research in our lifetime. "

Sir Paul Nurse, Cancer Research UK

Your research papers will be:

- available free of charge to the entire biomedical community

- peer reviewed and published immediately upon acceptance

- cited in PubMed and archived on PubMed Central

- yours - you keep the copyright
BioMedcentral 